\title{
A Psicologia e o Discurso Racial sobre o Negro: do “Objeto da Ciência” ao Sujeito Político
}

\author{
Lia Vainer Schucman \\ Universidade de São Paulo, SP, Brasil.
}

\author{
Hildeberto Vieira Martins \\ Universidade Federal Fluminense, RJ, Brasil.
}

\begin{abstract}
Resumo: O presente artigo descreve os principais elementos que constituíram o pensamento, a história e os posicionamentos éticos e políticos da Psicologia brasileira no que se refere às relações raciais. Estes elementos são alinhados e comentados da seguinte maneira: a) um primeiro debate que se inicia no fim do século XIX, no qual o pensamento psicológico sobre o problema racial descreve o negro como "objeto da ciência"; a ideia de raça é, neste ponto da história, determinada biologicamente; b) o período compreendido entre 1930 e 1960, caracterizado pelo impacto da obra de Gilberto Freyre, em que o conceito de raça aparece como determinante cultural e posteriormente foi marcado pela crítica ao mito da "democracia racial"; c) um momento que se inicia no fim da década de 1970, sob influência de estudos de desigualdades raciais, da abertura política e do processo de redemocratização do país, quando os movimentos sociais negros, através de seus atores, ativistas e intelectuais, produzem a ideia de raça como constructo social e pautam uma agenda política redefinindo o debate racial, e na qual a Psicologia passa a discutir o negro não mais como "objeto da ciência", mas sim como agente produtor de sua própria história.
\end{abstract}

Palavras-chave: Psicologia, História da Psicologia, Raça, Racismo.

\section{Psychology and Racial Discourse on Black People: from “Object of Science" to Political Subject}

\begin{abstract}
This article describes the main elements that constituted the thought, history, and ethical and political positions in Brazilian psychology in relation to race relations. These elements are aligned and commented as follows: a) a first debate that begins in the late nineteenth century, in which psychological thought about the racial problem describes black people as an "object of science"; the idea of race is, at this point in history, determined biologically b) the period between 1930 and 1960, characterized by the impact of the work of Gilberto Freyre, in which the concept of race appears as a cultural determinant and was later marked by criticism of the myth of "racial democracy"; c) a moment that began in the late 1970s under the influence of studies of racial inequalities, political opening, and the process of re-democratization of the country where black social movements through their actors, activists, and intellectuals produce the idea of race as a social construct and guide a political agenda redefining the racial debate, and in which psychology begins to discuss black people no longer as "objects of science" but as agents of their own history.
\end{abstract}

Keywords: Psychology, History of Psychology, Race, Racism. 


\title{
Psicología y Discurso Racial acerca del Negro: de “Objeto de la Ciencia” a Sujeto Político
}

\begin{abstract}
Resumen: En este artículo se describen los principales elementos que constituyen el pensamiento, la historia y las posiciones éticas y políticas de la psicología brasileña con respecto a las relaciones raciales. Tales elementos están alineados y comentados de la siguiente forma: a) un primer debate que se inicia a finales del siglo XIX, en que el pensamiento psicológico sobre el problema racial describe el negro como "objeto de la ciencia"; la idea de raza es, en este momento de la historia, determinada biológicamente; b) el período entre 1930 y 1960, caracterizado por el impacto de la obra de Gilberto Freyre, donde el concepto de raza aparece como un determinante cultural y que más tarde se caracterizó por la crítica del mito de la "democracia racial”; c) un momento que comienza a finales de la década de 1970, bajo la influencia de los estudios de desigualdades raciales, la apertura política y el proceso de redemocratización del país en que los movimientos sociales negros, a través de sus actores, activistas e intelectuales, producen la idea de raza como una construcción social y engendran una agenda política redefiniendo el debate racial, en la que la psicología va a discutir el negro ya no como "objeto de la ciencia", sino más bien como agente productor de su propia historia.
\end{abstract}

Palabras claves: Psicología, Historia de la Psicología, Raza, Racismo.

\section{Introdução}

Para se discutir a questão da igualdade social e política nas sociedades modernas, é preciso correlacioná-la obrigatoriamente à questão da cidadania e às conquistas de certos direitos jurídico-políticos, já que o modelo de cidadania e a ideia de democracia moderna são pensados como resultantes da estreita articulação entre a liberdade política, que é a capacidade de exercer tais direitos, e a igualdade social, que é a capacidade de gozar de tais direitos. Se nossa análise partir dessa perspectiva, podemos considerar que a cidadania - e o consequente processo democrático advindo de tal norte ideológico - foi estabelecida como uma resposta desenvolvida em decorrência da formação e consolidação de uma visão liberal da/na sociedade, presente já em finais do século XVIII. Esse fenômeno é o resultado mais evidente dos embates políticos produzidos como consequência das reconfigurações do espaço social que, a partir daquele momento, seria visto também como campo de conflito e cenário de evidenciação das dicotomizações de classe, que teve como consequência principal a separação produzida entre o Estado e a sociedade, entre o público e o privado (Sennet, 1988). Quando pensamos na sociedade brasileira, o que nos interessa são as ligações/relações pessoais, que acabam servindo como filtro para o acesso a direitos. As relações pessoais são tão importantes para esse livre trânsito social, que não ter relações pode implicar em um maior risco pessoal ou mesmo a produção de uma nulidade identitária enquanto agente portador de direitos, já que o que importa é saber "quem está falando" (DaMatta, 1997). E como a lógica hierárquica brasileira parece estar baseada na "intimidade social", ela acaba se tornando um dos fatores que têm maior peso na construção das relações sociais (DaMatta, 1997). O que pretendemos, a rigor, com esta presente reflexão, é discutir algumas dessas questões no campo das relações raciais no Brasil e destacar, neste cenário, o papel da Psicologia na tentativa de compreender como são produzidas formas de inclusão ou exclusão sociais garantidores (ou não) de direitos considerados balizadores de um certo ideário democrático (individual, social e político).

Nas últimas décadas, a produção científica da Psicologia despertou um novo interesse sobre a questão do racismo e das práticas ligadas ao preconceito e discriminação. Sem entrar no mérito ou na pertinência da retomada deste debate, é possível constatar que os psicólogos estão interessados na questão racial, em seus efeitos subjetivos e em seus respectivos impactos na produção do sofrimento psíquico (Costa, 2015; Martins, 2014; Nunes, 2006; Schucman, 2012; Tavares, Oliveira, \& Lages, 2013).

O objetivo desse artigo é discutir como um conjunto de ideias e práticas acadêmicas, institucionais e 
sociais foram elaboradas na imbricação entre a temática racial brasileira e a constituição de investigações e explicações psicológicas ${ }^{1}$ sobre a sociedade brasileira e seu funcionamento racializado. Essa tarefa começa com uma revisão da literatura que consideramos histórica e tematicamente relevantes para esse debate e finaliza com entrevistas e relatos de ações de atores sociais envolvidos nesta produção. Aqui não pretendemos uma revisão exaustiva, mas uma revisão da produção bibliográfica que indique a eclosão de "viradas analíticas" ou de novas maneiras de discutir a questão racial brasileira e de como essas rupturas alcançaram resultados importantes no debate nacional e internacional. O recurso metodológico que propomos nesse artigo fundamentar-se-á em um levantamento histórico, bibliográfico e documental de material relevante para o seu desenvolvimento e elaboração teórico-crítico. Analisaremos certos textos e documentos e as respostas apresentadas por determinados autores e aparelhos institucionais que versam sobre o campo dos discursos psicológicos (fontes primárias e secundárias). A seleção desse material documental foi definida a partir de marcos cronológicos que serão mais bem explicitados abaixo. Tal escolha levou em consideração a relevância histórica que essa documentação teve para a produção de estudos étnico-raciais no campo dos saberes psicológicos e sua imbricação com a sociedade brasileira. Contudo, a tarefa de arrolar toda a produção bibliográfica em Psicologia sobre o fenômeno racial e suas manifestações correlatas, vale dizer, não seria alcançada no escopo de um artigo. Não deixa de ser relevante afirmar também que tal inventário referencial venha sendo buscado cada vez mais nos últimos anos no âmbito da Psicologia (Bento, Silveira, \& Nogueira, 2014; Carone, \& Bento, 2002; Ferreira, 2000; Martins, \& Silva, 2013, 2014; Schucman, 2010, 2012; Santos, \& Schucman, 2015), e que esses trabalhos tenham revelado o quanto é importante o estudo da questão racial pela Psicologia para a compreensão do processo de democratização do nosso país e das concepções de cidadania desenvolvidos na consolidação da sociedade brasileira.
Elegendo três momentos nodais como emblemáticos e aglutinadores na elaboração de modos de pensar e dizer sobre "raça", a partir da retomada da Psicologia acima descrita, que serão mais bem aprofundados ao longo desse texto, o nosso propósito principal é contribuir para a ampliação de uma reflexão histórica, crítica e política para possíveis e bem-vindas articulações entre os saberes psi e o conceito de raça.

No campo das ciências sociais, biológicas e humanas, o conceito de raça é visto hoje como um constructo, ou seja: a raça não é considerada como uma existência concreta, mas sim o resultado de certos modelos e práticas vigentes em um determinado momento histórico. O mesmo ocorre com o conceito de "cor", que, apesar de ter uma forte conotação física (características fenotípicas), está sujeito a usos e definições ambíguas e subjetivas. Segundo Guimarães, isso ocorre por "falta de uma regra precisa de descendência racial" no Brasil, tal como ocorre nos Estados Unidos (Guimarães, 2005). Ainda segundo este mesmo autor, a "cor" é "mais que pigmentação da pele", vinculada fortemente ao processo de hierarquização social (Guimarães, 2005). O conceito de "raça" usado nesse trabalho, portanto, é o de "raça social", conforme teorizou Guimarães (1999), isto é, não se trata de um dado biológico, mas de "construtos sociais, formas de identidade baseadas numa ideia biológica errônea, mas eficaz socialmente, para construir, manter e reproduzir diferenças e privilégios" (p. 153). Para esse autor, se a existência de raças humanas não encontra qualquer comprovação no bojo das ciências biológicas, elas são, contudo, "plenamente existentes no mundo social, produtos de formas de classificar e de identificar que orientam as ações dos seres humanos" (p. 153). Nessa perspectiva, consideramos a raça como resultante de uma série de práticas discursivas produtoras de um "solo fértil" de significações - como o discurso racializado - e que resultam na produção de campos não-discursivos - ações, comportamentos explícitos ou implícitos - geradoras de sua permanência e insistência como definidora de um sujeito e de uma história.

\footnotetext{
${ }^{1}$ A utilização dessa expressão segue o entendimento já realizado por uma série de trabalhos em história da Psicologia. Esse termo tem sido utilizado para definir o campo discursivo que abarca as práticas produzidas pela psiquiatria, Psicologia e psicanálise no que tange ao entendimento e funcionamento daquilo que se convencionou chamar de "alma", comportamento, mente, "espírito", ou seja, o polo de oposição do que se convencionou chamar de uma "corporalidade estrita" (cf. Duarte, 1997; Duarte, Russo, \& Venâncio, 2005; Jacó-Vilela, Jabur, \& Rodrigues, 1999). Considera-se, portanto, os saberes psicológicos o conjunto de disciplinas que estudam os fatores psíquicos, à luz de uma concepção científica ou de caráter cientificizante, assim como suas relações estreitas com a descrição das categorias de normal e patológico.
} 
O propósito desse artigo é apresentar, em linhas gerais, três diferentes etapas históricas nas quais tentaremos demonstrar um enfoque psicologizante em torno da questão racial. Os critérios dessas escolhas se basearam na relevância e impacto histórico-social de personagens e de fatos para a constituição de um debate psicológico sobre a temática racial e para o engendramento de formas de inclusão/exclusão do lugar político e social de determinada parcela da nossa sociedade (exercícios de cidadania).

Definimos como estratégia de análise a demarcação de fronteiras operativas, que seguem delimitações histórico-cronológicas, capazes de nos auxiliar nessa discussão. Consideramos que as questões levantadas e as respostas produzidas em torno da interface entre os saberes psicológicos e a questão racial, que vão produzir uma mudança na forma de pensar o papel e o lugar social de determinados agentes sociais, podem ser divididas da seguinte maneira: a) um primeiro debate que se inicia entre o fim do século XIX e o início do século XX (1890-1920) no qual o pensamento médico-psicológico sobre o problema racial descreve o "negro"2 como "objeto da ciência", ao mesmo tempo em que a ideia de raça é compreendida como conceito biológico e o racismo é naturalizado. Esse período foi marcado pelos estudos médico-psicológicos iniciados pela "Escola Baiana de Antropologia" (Raimundo Nina Rodrigues e seus discípulos); b) o período de 1930 até 1960, caracterizado pelo impacto da obra de Gilberto Freyre, em que o conceito de raça aparece como determinante cultural onde o racismo se justifica através da falsa ideia de hierarquias culturais que posteriormente foi marcado pela crítica ao mito da "democracia racial", e por último, c) um momento que se inicia na década de 1970, sob influência de estudos de desigualdades raciais, quando a raça é compreendida como constructo social que determina as desigualdades simbólicas e materiais da população negra. Esse é o momento em que trabalhos em torno do conceito de branqueamento/branquitude, de debates voltados para a criação de ações de promoção da igualdade étnico-racial no Brasil e também sobre a questão da identidade, começam a ocupar espaço nas pesquisas em Psicologia. A partir desse momento, o papel da Psicologia de seu compromisso social é revisado através da "crise" pela qual passará enquanto área de conhecimento. Não por acaso esse momento histórico foi caracterizado pelos primeiros movimentos sociais de redemocratização em nossa sociedade. Ao que parece, a revisão científica no campo da Psicologia, em especial o da Psicologia Social, e a luta democrática pela ampliação dos direitos sociais e políticos ganham força ao mesmo tempo em nossa sociedade. Essa "crise" científica favoreceu a ampliação dos seus campos de estudo, incluindo aí o tema do racismo.

Definidos os marcos cronológicos, passemos para a elaboração de um quadro de análise dessas etapas.

\section{O debate inicial sobre o problema racial: o negro como "objeto da ciência"}

$\mathrm{Na}$ literatura sobre a questão racial brasileira (Antunes, 1999; Corrêa, 1982; 1998; Engel, 2001; Leite, 2002; Oda, 2003; Schwarcz, 1993; Skidmore, 1976), é bastante comum definir como marco inicial os trabalhos médico-psicológicos de Raimundo Nina Rodrigues (1862-1906). Seus estudos tomavam como questão principal uma maior compreensão do papel da população negra, africana ou afro-brasileira, na constituição da sociedade brasileira a partir do conceito-chave de "degeneração da raça". Os trabalhos de Rodrigues $(1894,1935,1939,2006)$ foram fundamentais para a consolidação de um modelo psicofísico capaz de nomear e descrever as "deficiências" do negro brasileiro, tendo como efeito mais imediato o reconhecimento das consequências sociais "perversas" que a manutenção do convívio com essa raça poderia acarretar para a sociedade brasileira. Tal chave interpretativa teve continuidade no início do século XX a partir da retomada de suas ideias feita por alguns dos seus "discípulos", como Ramos (1934, 1937, 1939) e Peixoto (1898, 1938a, 1938b), por exemplo, e que consolidaram o que passou a ser chamada de "Escola Baiana". Arthur Ramos foi um autor bastante atento e interessado nas questões raciais e nos problemas que supostamente seriam gerados pela cultura negra (Ramos, 1934, 1937). Segundo Fernando Sales, responsável pelas notas bibliográficas de Nina Rodrigues em seu livro Os africanos no Brasil, essa "Escola" teve ainda como discípulos ilustres Heitor Carrilho, Diógenes Sampaio, Oscar Freire, Alcântara Machado, Flamínio Fávero, Estácio de Lima, Ulysses Pernambucano,

\footnotetext{
${ }^{2}$ No período aqui comentado, a questão racial relacionada à população negra e ao seu papel social era circunscrita de maneira genérica pela expressão "problema negro", como presente em Rodrigues (1935) e outros autores da época. Nesse sentido, a questão de gênero não era enfatizada e, portanto, as particularidades relacionadas a essa questão não ocupava significativo espaço nesse debate.
} 
entre outros (Sales, 1988). As pesquisas e ações institucionais realizadas por esses atores foram de grande importância para a formação de um saber e de uma prática médico-psicológica sobre a questão racial no Brasil nas primeiras décadas republicanas. O "negro" seria "capturado" nessa rede de significações como elemento portador de certas características patologizáveis e, portanto, passível de ser "objeto da ciência". Nina Rodrigues e a sua "Escola", portanto, contribuíram significativamente para a incrementação de determinadas áreas de saber, como a psiquiatria e a medicina legal (Antunes, 1999; Oda, 2003; Schwarcz, 1993), a psicanálise (Costa, 2007) e a antropologia brasileiras (Corrêa, 1982, 1998). Além disso, esses intelectuais contribuíram para a difusão de certas temáticas ligadas ao racismo científico (Leite, 2002; Skidmore, 1976) ou do estudo das manifestações culturais africanas (Fry, \& Maggie, 2006; Ramos, 2007).

O discurso racial presente na obra de Nina Rodrigues, definidor de um padrão de normalização da sociedade - a manutenção das hierarquias -, seria substituído por um modelo de mestiçagem menos pessimista e mais viável para um país ainda em construção, cujo propósito era produzir um discurso mais eficaz, de controle, sobre esse "elemento negro". O que vai se produzir é uma espécie de transliteração: a passagem de um modelo racial para um modelo culturalista. Isso marca, no entanto, menos a mudança do "objeto" de análise que a continuidade de práticas de controle social, isto é, a determinação das positividades e/ou negatividades desse "objeto". Um exemplo desse exercício foi a tentativa empreendida por Arthur Ramos em "atualizar" o discurso de Nina Rodrigues a partir de seu projeto culturalista, tomado emprestado do campo da antropologia.

\section{Uma mudança de perspectiva? Pensando a cultura como salvação}

Podemos afirmar que a década de 1930 e as seguintes foram caracterizadas pela difusão do modelo sociocultural de cunho freyriano - e posteriormente por sua revisão crítica. Esse período também foi determinado pelas tentativas iniciais de formalização da Psicologia como disciplina independente no ensino superior (Lourenço Filho, 1994; Brozek, \& Massimi, 1998) e da produção concomitante do que poderíamos chamar de uma ainda incipiente "Psicologia Social", como afirmam alguns autores (Bonfim, 2003; 2004; Sá, 2007). Percebe-se que os nos- sos intelectuais (cientistas, literatos etc.) começam a criticar o modelo do determinismo racial e pensar uma alternativa para se pensar o Brasil e seus impasses. As décadas iniciais do século XX foram marcadas pelo projeto político-social de um Brasil moderno, projeto construído na confluência de várias disputas e embates e que culminariam naquilo que ficou conhecido como a "Revolução de 1930", processo histórico gerador do período denominado posteriormente de Estado Novo. A partir dessa nova ordem republicana, foi sendo fomentada a tentativa de um novo modelo de Brasil (Herschmann, \& Pereira, 1994). Vemos surgir um outro olhar que gira em torno da questão da miscigenação racial brasileira, mas agora com uma roupagem positiva. Nesse período, certos autores passam a discutir como essa "positividade" afetava a nossa identidade nacional e o nosso futuro enquanto nação. Gilberto Freyre (1900-1987) é considerado o principal representante desse modelo (1933; 2000). Contudo, outras análises surgiram com o mesmo propósito de sinalizar para a nossa mistura racial e seu impacto em nossa identidade nacional. Os trabalhos de Arthur Ramos de Araújo Pereira (1903-1949) seguem essa perspectiva (Ramos, 1934; 1937; 1939).

Nas primeiras décadas do século passado, Arthur Ramos analisou e observou a reconfiguração das tradições africanas que, em contato com o elemento português e com os nossos grupos autóctones, influenciaram os hábitos de vida, instituições e folclore da sociedade brasileira (1934, 1937, 2007). Nos seus trabalhos voltados para essa temática, percebe-se que o autor ainda seguia os passos do "mestre" Nina Rodrigues. Esse período também é o cenário da realização dos primeiros cursos universitários em que a Psicologia Social é discutida, como os ministrados pelo próprio Arthur Ramos, por Raul Briquet (1887-1953) e Donald Pierson (1900-1995). Os trabalhos de Elisabeth Bomfim $(2003,2004)$ afirmam que Raul Briquet ministrou o primeiro curso superior de Psicologia Social na Escola Livre de Sociologia e Política de São Paulo, ligada à Universidade de São Paulo (USP), no segundo semestre de 1933. Já o segundo curso foi de autoria de Arthur Ramos, este acontecido na Escola de Economia e Direito, na Universidade do Distrito Federal (UDF), em 1935. Segundo o próprio autor, a sua extinção deu-se no mesmo momento do fechamento dessa Universidade, em 1937 (Ramos, 1939).

O projeto de divulgação e de tentativa de consolidação de um debate psicológico no Brasil avançou 
com a publicação de livros com títulos que fazem alusão ao campo. Foram publicados, respectivamente, o livro Psicologia Social, de autoria de Briquet, editado em 1935, e o livro de Ramos de Araújo, Introdução à Psicologia Social, editado em 1936. Esse livro contou com uma reedição organizada pelo Conselho Federal de Psicologia (CFP) em 2003 (Ramos, 2003). E o terceiro curso de Psicologia Social foi realizado por Donald Pierson na década de 1940, na Escola Livre de Sociologia e Política de São Paulo. Esse autor considerava que o principal fator que impedia o processo de integração do negro à sociedade brasileira era o preconceito racial (Guimarães, 2005). A década de 1950 foi marcada pelos estudos sobre relações raciais patrocinados pelo ciclo de pesquisas comparativas organizado pela Organização das Nações Unidas para a Educação, a Ciência e a Cultura (Unesco) em diferentes regiões brasileiras, ocorridos nos anos de 1951 e 1952. O objetivo de tais pesquisas era demonstrar a existência de experiências exitosas de cooperação racial no mundo. O projeto da Unesco marcou a ruptura de uma visão idílica sobre as relações raciais no Brasil e colocou em xeque a ideia de democracia racial brasileira. Os estudos iniciados a partir do projeto Unesco são aqui pensados como fatores definidores de uma nova maneira de discutir a questão racial brasileira. Não por acaso, para alguns autores, esses estudos determinaram uma outra forma de entender a questão das relações raciais, permitindo uma outra nomeação para essa problemática, ou seja, já não mais tratar-se-ia de "democracia racial" mas sim de "racismo à brasileira" (Telles, 2003) ou o "mito da democracia racial" (Guimarães, 2002).

A pesquisa financiada pela Unesco, realizada na Bahia, Pernambuco, Amazonas, Rio de Janeiro e São Paulo deslocou a discussão racial brasileira do paradigma cultural freyriano para o paradigma sociológico construído por Florestan Fernandes (Maio, 2000). A etapa realizada em São Paulo foi coordenada por Roger Bastide e Florestan Fernandes, tinha o intuito investigar como se constituíam as relações raciais entre brancos e negros (Bastide, \& Fernandes, 1955) e contou com a participação de três profissionais ligados ao campo psicológico: Virgínia Leone Bicudo (1915-2003), Aniela Meyer Ginsberg (1902-1986) e Otto Klineberg (1899-1992). Virginia Leone Bicudo, sob a orientação de Donald Pierson, defendeu sua dissertação de mestrado também voltada para o estudo das relações raciais (Estudo de atitudes raciais de pre- tos e mulatos em São Paulo), recentemente publicada (Bicudo, 2010). Ginsberg (1955) realizou a investigação que teve como título Pesquisa sobre as atitudes de um grupo de escolares em São Paulo em relação com as crianças de cor. Já Otto Klineberg foi um pioneiro no campo da Psicologia Social nos Estados Unidos, inclusive participando de pesquisas sobre relações raciais nesse país na década de 1940. Logo depois de seus primeiros trabalhos nesse campo ele foi convidado a lecionar na USP como professor da disciplina de Psicologia nessa Universidade entre os anos de 1945 e 1947, publicando livros sobre Psicologia Social e relações raciais. Herdeiro e seguidor dessa tradição crítica dos estudos raciais e importante personagem do campo da Psicologia Social, Dante Moreira Leite (1927-1976) - que foi assistente de Annita Cabral na cadeira dessa área na USP - publicou livros que tratavam do problema racial (Leite, 2002; 2008). O seu principal trabalho, intitulado $\mathrm{O}$ caráter nacional brasileiro, foi escrito em 1954 e contou com algumas reedições em decorrência do impacto e da abrangência de sua influência (Paiva, 2000). O livro é importante porque sua questão principal é demonstrar o quanto o projeto nacional brasileiro foi marcado por uma ideologia racial. A década de 1950 marcou o declínio do que chamamos anteriormente de uma perspectiva positiva sobre a questão racial, produto de uma revisão pensada por certos intelectuais sobre as possíveis saídas para os impasses que a questão racial brasileira tinha gerado em nossa sociedade. Contudo, as pesquisas realizadas pelo projeto Unesco romperam com essa perspectiva ao formularem outra leitura (mais crítica) sobre o mesmo problema (Maio, 2000). Para esses novos atores, é a desigualdade social brasileira que fomenta uma desigualdade racial, e produz o preconceito racial em nosso país. Essa década ainda seria marcada pelo surgimento dos primeiros cursos de Psicologia - ainda um misto de sociologia, Psicologia, educação e outros ingredientes misturados a esse processo alquímico -, e de um debate ora positivo, ora negativo sobre as relações raciais no Brasil.

\section{Nem sangue, nem cultura: redemocratização política e raça como construção social}

A década de 1970 começa com a conquista brasileira de mais uma Copa do Mundo e a certeza de que um "milagre" econômico brasileiro (1968-1973) estava em curso. O final dessa mesma década já aponta para 
o desgaste e a fragilidade de suas garantias e ideias, verificado pelo aumento da participação popular e política que buscava construir um verdadeiro projeto democrático no Brasil. Isso pode ser constatado pela ação dos movimentos sindicais do ABC paulista e pelo movimento pela anistia dos presos e exilados políticos que conseguiu aprovação da Lei de Anistia - Lei $\mathrm{n}^{\circ}$ 6.683/1979 (Brasil, 1979). Não parece ser por acaso que, em 1979, os estudos de raça e racismo no Brasil mudam radicalmente a forma de compreender as relações sociais entre negros e brancos. $\mathrm{O}$ trabalho do sociólogo Hasenbalg (1979) aparece como um marco dentro dos estudos sobre relações raciais no país. Assim como os trabalhos da Unesco, o autor desvela a ideia falaciosa de democracia racial e aponta para as desigualdades raciais não apenas como produto do sistema escravocrata, mas sim produto de uma sociedade racista e discriminatória naquele momento. Ou seja, Hasenbalg foi o primeiro teórico dentro da tradição dos estudos raciais brasileiros que apontou o racismo para além da função de estruturas e privilégios de classe.

A tese central do autor, e que é também oposta à tese da escola paulista de sociologia, é que a raça é componente importante nas estruturas sociais, ou seja, a exploração de classe e a opressão racial se articularam como mecanismos de exploração do povo negro, e este processo resulta nas desigualdades de bens materiais e simbólicos da população negra. Hasenbalg demonstra como, através de mecanismos racistas, negros nascidos na mesma condição social que brancos tem menores possibilidades de ascensão social, além de sofrerem uma desvantagem competitiva em todas as fases da sequência de transmissão de status. Hasenbalg demonstra como a opressão racial beneficia não só capitalistas brancos como também brancos não capitalistas. Desta forma, a maioria dos brancos tem vantagens tanto com a opressão racial, quanto com o racismo, pois são os mecanismos racistas que fazem com que a população branca tenha vantagem no preenchimento das posições da estrutura de classes que comportam privilégios matérias e simbólicos mais desejados. Além disso, os brancos têm privilégios menos concretos, mas que, no entanto, são fundamentais no que se refere ao sentimento e a constituição da identidade dos indivíduos, tais como honra, status, dignidade e direito à autodeterminação (Hasenbalg, 1979).

A partir deste estudo, a categoria raça passa a ser compreendida pelos estudiosos do tema como constructo social, retirando qualquer caráter de cunho cultural e biológico, ou seja, essencialista, das populações racializadas. Neste sentido, os estudos do campo da Psicologia também passam a compreender a raça como categoria social, que constitui, diferencia, hierarquiza e localiza os sujeitos em nossa sociedade. Portanto, a partir daí as produções da Psicologia e principalmente da Psicologia Social, passam a pensar o fenômeno do racismo do ponto de vista psicossocial e não psicologizante, pois não localizam no sujeito discriminado a responsabilidade pela discriminação racial que vive cotidianamente, e sim nas relações de poder entre diferentes grupos, evidenciando a força dessa categoria como fator de diferenciação e de hierarquização social. Nesse momento a Psicologia Social brasileira é chamada a responder a esse problema, principalmente por agentes dos movimentos sociais negros, e a prestar contas da lacuna em sua produção no que se refere aos estudos das relações raciais. A partir da década de 80 do século passado, surge um movimento em que o enfoque dos trabalhos tanto teóricos como de intervenção do psicólogo é concentrado nos efeitos psicossociais do racismo. Marco desta nova geração para a Psicologia é o livro Tornar-se negro: As vicissitudes da Identidade do Negro Brasileiro em Ascensão Social da psicóloga e psicanalista Neusa Santos Souza, publicado em 1983 e prefaciado pelo psicanalista Jurandir Freire Costa. Tornar-se negro traz um olhar analítico para os efeitos da ideologia do embranquecimento e do racismo na construção da subjetividade do negro brasileiro. E através de análises minuciosas o racismo é compreendido como uma violência no corpo e na subjetividade negra, já que nossa sociedade construiu a noção de belo, harmônico, e por fim de humano a partir dos parâmetros brancos. Ainda, este é o momento em que temos no Brasil a chamada "crise da Psicologia Social", em que os psicólogos, que podem ser aqui representados pela figura de Silvia Lane, denunciam os usos ideológicos da Psicologia Social (de orientação norte-americana), essencialmente de base experimental, e que foi reproduzida no Brasil como uma ciência alinhada com os interesses adaptativos, alinhados ao modelo liberal e capitalista, uma ciência individualizante e sem compromisso social com a realidade brasileira e latino-americana. Um dos resultados dessa crise foi o surgimento da Associação Brasileira de Psicologia Social (Abrapso), que procurou integrar as demandas oriundas dos movimentos sociais e de certos setores da própria Psicologia para construir uma Psicologia 
comprometida com as comunidades locais. Aqui a Psicologia é convocada a pensar nas desigualdades sociais, políticas e raciais de nosso país e com isso promover sua desnaturalização. Para nós, não parece ser por acaso que as discussões sobre uma "virada" na Psicologia ocorram no momento em que no Brasil estávamos reivindicando uma sociedade mais justa e democrática, que lutávamos pelo reestabelecimento dos direitos democráticos e pelo fim de uma ditadura militar, ou seja, os debates que ocorriam na Psicologia podem ser vistos como reverberações de questões que estavam na "ordem do dia".

Nesta mesma perspectiva, já passadas algumas décadas e consolidado o processo de retomada democrática no país, com o intuito de retirar o olhar das pesquisas do negro e recolocar o problema nas relações de poder é publicado no ano de 2002 o livro Psicologia Social do Racismo: estudos sobre branquitude e branqueamento no Brasil. Os capítulos são de autoria de diversos pesquisadores, e o trabalho foi organizado pelas psicólogas Iray Carone e Maria Aparecida Silva Bento. É neste livro que Maria Aparecida Silva Bento traz pela primeira vez o conceito de branquitude para a compreensão das desigualdades raciais brasileiras e demonstra os privilégios simbólicos e materiais que os brancos obtêm na sociedade brasileira, por sua vez estruturada pelo racismo. Nesta mesma obra Fúlvia Rosenberg e Edith Piza publicam o artigo Cor nos censos brasileiros, trabalho fundamental para a compreensão da dimensão histórica e social das classificações raciais e seus efeitos nas construções das identidades raciais brasileiras. A partir de então, diferentes pesquisas na área da Psicologia são produzidas com o intuito de denunciar as desigualdades raciais, compreender os modos de subjetivação do racismo nos brancos e nos negros e, por último, propor intervenções possíveis em diferentes áreas de atuação dos psicólogos (Schucman, Nunes, \& Costa 2017). Dentro deste espectro de pensar a atuação do psicólogo no combate ao racismo, as diferentes produções acadêmicas surgidas a partir da década de 80 do século passado apontaram que a Psicologia tem um papel fundamental no combate ao racismo, já que o psicólogo está presente em diferentes campos da vida social onde as desigualdades raciais se ancoram, tais como: trabalho, setor organizacional, educação, assistência social, justiça, clínica, entre outros. Desse modo, com o propósito de atuar diretamente na interface da Psicologia com as vítimas do racismo, surge em São Paulo na década de 1990 duas organizações não governamentais (ONG) que são até hoje referências para o campo da Psicologia no combate ao racismo. O Centro de Estudos das Relações de Trabalho e Desigualdades (Ceert) foi criado em fevereiro de 1990. Uma de suas fundadoras e hoje atual diretora executiva é a psicóloga social Maria Aparecida Silva Bento. A importância deste centro no âmbito da Psicologia social e sua interface com a promoção de igualdade racial é ampla, pois o centro, na figura das psicólogas Maria Aparecida Silva Bento e Edna Muniz foi fundamental para interpelar e apoiar diferentes ações no combate ao racismo nas relações de trabalho e saúde, e principalmente articular junto a categoria de psicólogos publicações, seminários, congressos, mesas redondas e projetos sociais referentes à Psicologia das relações raciais. Dentre estas diferentes ações podemos destacar a publicação do Ceert no ano de 2014 em parceria com a Casa do Psicólogo do livro Identidade, branquitude e negritude - contribuições para a Psicologia Social no Brasil: novos ensaios, relatos de experiência e de pesquisa. Logo após, foi fundado em 1995 por um grupo de quatro psicólogas negras, Silvia de Souza, Marilsa de Souza Martins, Ana Maria Silva e Maria Lucia da Silva, o Instituto AMMA Psique e Negritude. A criação do instituto partiu do pressuposto de que, para além da via política, era necessário, para desmantelar o racismo, também desconstruir os efeitos psicossociais gerados por ele. Neste momento, as produções da Psicologia como o trabalho de Neusa Souza Santos Tornar-se Negro e o clássico livro de Frantz Fanon Peles Negras, Máscaras Brancas já haviam demonstrado que o racismo prejudica a

saúde psíquica dos indivíduos, podendo fazê-los desenvolver sintomas psicossomáticos, inibições, impedimentos (de acesso, de participação), especialmente na experiência de negritude el ou desenvolver uma autoimagem distorcida, descolada da própria realidade e racialidades (Silva, 2016) ${ }^{3}$.

\footnotetext{
${ }^{3}$ Citação da fala da atual diretora presidente da ONG Maria Lucia Silva no dia 11 de maio em conversa com autor do texto.
} 
Desde então, o instituto tem buscado, por meio de formação e práticas clínicas, identificar, elaborar e desconstruir o racismo e seus efeitos psicossociais ${ }^{4}$.

O instituto AMMA Psique e Negritude ao lado do Ceert tem sido, nos últimos 20 anos, um dos maiores interlocutores entre movimento social organizado e a categoria de psicólogos e, desde então, tem promovido intervenções através de debate, ciclos formativos, e uma clínica psicológica com atendimentos individuais e grupais. É quando, com a articulação destas duas organizações representadas por Maria Lucia da Silva e Maria Aparecida Silva Bento juntamente com a psicóloga recifense Maria de Jesus Moura do Observatório Negro, a categoria de psicólogos, a partir dos sistemas conselhos, é pressionada a se posicionar politicamente com a luta antirracista, fruto desta articulação entre movimentos sociais e categoria - através das comissões de direitos humanos do CFP coordenada na época pelo psicólogo social Marcus Vinícius de Oliveira Silva. Em janeiro de 2002, o Sistema Conselhos lança uma campanha nacional com o slogan "preconceito racial humilha, a humilhação faz sofrer" ${ }^{5}$ divulgada em todas as sedes regionais. No mesmo ano, a psicóloga Maria de Jesus Moura, também integrante da Comissão de Direitos Humanos do CFP, propõe a elaboração de algumas normas de atuação para orientar os psicólogos relativas ao preconceito e à discriminação racial. Essas normas deram origem à Resolução nº 018/2002 (Conselho Federal de Psicologia, 2002), assinada pelo então presidente Odair Furtado.

Os principais artigos desta resolução são: (i) os psicólogos não exercerão qualquer ação que favoreça a discriminação ou preconceito de raça ou etnia; (ii) os psicólogos, no exercício profissional, não serão coniventes e nem se omitirão perante o crime do racismo; (iii) os psicólogos não se utilizarão de instrumentos ou técnicas psicológicas para criar, manter ou reforçar preconceitos, estigmas, estereótipos ou discriminação racial e (iv) os psicólogos não se pronunciarão nem participarão de pronunciamentos públicos nos meios de comunicação de massa de modo a reforçar o preconceito racial.

Estas duas ações foram o pontapé inicial para uma série de eventos, criações de grupos de trabalho e atividades de formação e sensibilização para o tema das relações raciais e racismo dentro da categoria. E, desta forma e aos poucos, uma maior adesão de estudantes e profissionais de Psicologia em sua maioria negros e negras começam a estudar, escrever, pesquisar e intervir na e para a promoção de igualdade racial na saúde, educação, mundo do trabalho, assistência social, entre outros. Pode-se dizer que estas articulações entre movimentos sociais, categoria e universidade foram os fatores que culminaram na realização do I Encontro Nacional de Psicólogos(as) Negros(as) e Pesquisadores sobre Relações Raciais e Subjetividade no Brasil - I Psinep, ocorrido durante três dias, em outubro de 2010, no Instituto de Psicologia da Universidade de São Paulo (IPUSP) e que contou com aproximadamente 200 participantes presentes, nacionais e internacionais, e mais de 500 ouvintes a distância que acessaram a transmissão ao vivo. Aqui é importante ressaltar que apesar de ter sido um evento científico-acadêmico, com apoio do Departamento de Psicologia Social e do Trabalho da USP e do Sistemas Conselhos, a Comissão Organizadora foi composta pelas próprias organizações negras em conjunto com um instituto de Psicologia; são elas: Ceert, São Paulo - SP; Centro de Estudos e Defesa do Negro do Pará (Cedenpa), Belém - PA; Instituto AMMA Psique e Negritude, São Paulo - SP; Instituto Silvia Lane de Psicologia e Compromisso Social, Salvador BA; Maria Mulher - Organização de Mulheres Negras, Porto Alegre - RS; Observatório Negro (ONEG), Recife PE; Rede de Mulheres Negras do Paraná, Curitiba - PR. Dentre os diversos resultados do I Psineo destacamos primeiramente a criação da Articulação Nacional de Psicólogas(os) Negras(os) e Pesquisadoras(es) (ANPSINEP) - que tem como principal objetivo garantir que o tema das relações raciais apareça de fato na agenda da Psicologia brasileira - e a redação de um documento final do encontro intitulado Carta de São Paulo (2011), assinado por todos os presentes que apontou caminhos teóricos, metodológicos e ético-políticos para os psicólogos. Citamos um trecho:

[...] O racismo à moda brasileira constitui um dos mais sofisticados e enigmáticos mecanismos que operando por meio da violência sistemática e silenciada, produz e torna cada vez mais agudas as desigualdades sociais, que no Brasil, tem também um viés eminentemente racial [...].

\footnotetext{
${ }^{4}$ Informações obtidas em conversa com a atual diretora presidente da ONG Maria Lucia Silva no dia 11 de maio de 2016 e no site http://www.ammapsique.org.br/.

${ }^{5}$ Para maiores informações, ver em http://site.cfp.org.br/campanhas/preconceito-racial/.
} 
Dessa forma, as propostas aqui elencadas [...] apontam decisivamente para um compromisso de todas(os) as(os) presentes com a construção de uma psicologia efetivamente comprometida com a superação do racismo brasileiro apontando as especificidades da contribuição da psicologia em relação a este tema (Carta de São Paulo, 2011).

É, portanto, através da pressão e articulação das organizações negras e de diferentes psicólogas, mulheres negras, como Neusa Santos Souza, Edna Roland, Edna Muniz, Maria Jesus Moura, Maria Aparecida Silva Bento, Isildinha Baptista Nogueira, entre outras, que a temática das relações raciais e do racismo começa desde a década de 1980 até os dias atuais a tomar corpo na produção de conhecimento dentro da área da Psicologia, nos debates com a categoria e também na atuação dos psicólogos. E nesse sentido, vale dizer que os temas do racismo, do preconceito, dos estereótipos e da discriminação, como já demonstrado neste texto, sempre fizeram parte das grades curriculares dos cursos de Psicologia social (Santos, Schucman, \& Martins, 2012). No entanto, é somente depois da década de 1980 que o tema passa a ser compreendido dentro da Psicologia não apenas como um fenômeno social a ser estudado, mas sim como um fenômeno ligado às relações de poder estruturais de nossa sociedade e, portanto, uma temática que demanda comprometimento ético-político ligado aos direitos humanos e a luta antirracista. Podemos, assim, dizer que é a partir do olhar do negro para a Psicologia, e não mais da Psicologia em relação ao negro como objeto, que a Psicologia Social brasileira passa a se comprometer de fato com o combate ao racismo.

\section{Considerações finais}

Pudemos ver aqui, em linhas gerais, como a questão racial esteve presente na construção histórica dos saberes psicológicos no Brasil e, consequentemente, do brasileiro ao longo de sua história. Também vimos como os saberes psicológicos se somaram a esse debate desde muito cedo, propondo maneiras de pensar e intervir sobre a questão do negro já a partir de finais do século XIX. Como afirmado anteriormente, nosso objetivo não foi produzir um estudo definitivo sobre o assunto. O foco aqui é apresentar o que consideramos como pontos capitais que podem auxiliar em uma discussão introdutória sobre as relações entre determinada produção em Psicologia Social e a questão racial. Retratou-se, portanto, os principais eventos, ideias e atores que possibilitam a compreensão de como se deu a construção de projeto da sociedade brasileira marcado por um "credo racial". E se nós apontamos como início desse processo os estudos de Raimundo Nina Rodrigues sobre a população africana e afro-brasileira já em finais do século XIX, fechamos esse périplo afirmando que os estudos de branquitude e branqueamento (Carone, \& Bento, 2002), juntamente com a participação e pressão dos movimentos sociais negros, foram respectivamente fundamentais para a mudança de olhar da Psicologia sobre as relações raciais. Expor como o racismo constrói as identidades raciais brancas a partir de privilégios simbólicos e materiais demonstrou que estes privilégios, intencionalmente ou não, têm um papel importante na manutenção e legitimação das desigualdades raciais (Schucman, 2012). Apontamos ainda que a Psicologia se torna cada vez mais comprometida com a formação de uma sociedade mais justa e igualitária por conta de uma maior aproximação com os movimentos sociais, inclusive o movimento negro. Aqui é importante realçar que não consideramos mera coincidência que perspectivas mais progressistas na Psicologia relacionadas às questões raciais surjam no fim da década de 1970 e início de 1980, no período da luta pela anistia, das comunidades eclesiais de base, do movimento trabalhista do ABC, e, no caso da Psicologia, como já apontado anteriormente, o surgimento da Abrapso e gestões no Sistema Conselhos de Psicologia que incorporam paulatinamente as demandas levantadas e reivindicadas pelos movimentos sociais e intelectuais negros.

Para isso, a Psicologia construiu novos espaços na academia e em nossa categoria profissional para que o tema do racismo seja debatido como um dos fenômenos estruturais da nossa sociedade e para a compreensão das desigualdades sociais produzidas. Apesar de a Psicologia hoje já ter construído uma variedade de trabalhos sobre esse assunto e, portanto, de conhecimento sobre a temática aqui discutida, encontramos ainda pouca atenção da categoria como um todo - principalmente no que diz respeito aos cursos de formação de psicólogos - para a compreensão e engajamento na temática e também para a produção de respostas adequadas ao que tange à redução do racismo e seus efeitos. 


\section{Referências}

Antunes, J. L. F. (1999). Medicina, leis e moral: pensamento médico e comportamento no Brasil (1870-1930). São Paulo, SP: Fundação Editora UNESP.

Bastide, R., \& Fernandes, F. (1955). Relações raciais entre brancos e negros em São Paulo. São Paulo, SP: Editora Anhembi/UNESCO.

Bento, M. A. S., Silveira, M. J., \& Nogueira, S. G. (2014). Identidade, branquitude e negritude - contribuições para a psicologia social no Brasil: novos ensaios, relatos de experiência e de pesquisa. São Paulo, SP: Casa do Psicólogo.

Bicudo, V. L. (2010). Estudo de atitudes raciais de pretos e mulatos em São Paulo. São Paulo, SP: Sociologia e Política.

Bonfim, E. M. (2004). Históricos cursos de Psicologia Social no Brasil. Psicologia \& Sociedade, 16(2), 32-36. https://doi.org/10.1590/S0102-71822004000200005

Bonfim, E. M. (2003). Contribuições para a história da psicologia social no Brasil. In A. Jacó-vilela, D. Mancebo, \& M. L. Rocha (Orgs.), Psicologia social: relatos da América Latina (pp. 123-144). São Paulo, SP: Casa do Psicólogo.

Brasil. (1979, 28 de agosto). Lei № 6.683, de 28 de agosto de 1979. Concede anistia e dá outras providências. Diário Ofcial da União.

Brozek, J. \& Massimi, M. (Orgs.). (1998). Historiografia da psicologia moderna. São Paulo, SP: Loyola.

Carone, I., \& Bento, M. A. S. (2002). Psicologia social do racismo: estudos sobre branquitude e branqueamento no Brasil. Petrópolis, RJ: Vozes.

Carta de São Paulo (2011). In Anais do I Encontro Nacional de Psicólogos(as) Negros(as) e Pesquisadores(as) sobre Relações Interraciais e Subjetividade no Brasil (p. 83-85). Recuperado de http://anpsinep.cfp.org.br/wp-content/uploads/sites/24/2012/06/i-psinep-aqui-estamos.pdf

Conselho Federal de Psicologia. (2002). Resolução CFP no 018/2002, de 19 de dezembro de 2002. Estabelece normas de atuação para os psicólogos em relação ao preconceito e à discriminação racial. Brasília, DF: o autor.

Corrêa, M. (1982). Antropologia \& medicina legal: variações em torno de um mito. In C. Vogt, Caminhos cruzados: linguagem, antropologia e ciências naturais (pp. 53-63). São Paulo, SP: Brasiliense.

Corrêa, M. (1998). As ilusões da liberdade: a Escola Nina Rodrigues e a antropologia no Brasil. Bragança Paulista, SP: EDUSF.

Costa, E. S. (2015). Racismo como metaenquadre. Revista do Instituto de Estudos Brasileiros, (62), 146-163. https://doi.org/10.11606/issn.2316-901X.v0i62p146-163

Costa, J. F. (2007). História da Psiquiatria no Brasil: um corte ideológico. São Paulo, SP: Garamond.

DaMatta, R. (1997). Você sabe com quem está falando? Um ensaio sobre a distinção entre Indivíduo e Pessoa no Brasil. In R. DaMatta, Carnavais, malandros e heróis: para uma sociologia do dilema brasileiro (pp. 139-193). Rio de Janeiro, RJ: Zahar.

Duarte, L. F. D. (1997). Introdução: a análise da pessoa moderna pela história e etnografia dos saberes psicológicos. Cadernos do IPUB/UFRJ, (8), 1-10.

Duarte, L. F. D., Russo, J., \& Venâncio, A. T. (Orgs.). (2005). Psicologização no Brasil: atores e autores. Rio de Janeiro, RJ: Contra Capa.

Engel, M. G. (2001) Os delírios da razão: médicos, loucos e hospícios (Rio de Janeiro, 1830-1930) (Coleção Loucura \& Civilização). Rio de Janeiro, RJ: Editora Fiocruz.

Ferreira, R. F. (2000). Afro-descendente: identidade em construção. São Paulo, SP: EDUC.

Freyre, G. (1933). Casa grande \& senzala. Rio de Janeiro, RJ: José Olympio.

Freyre, G. (2000). Sobrados e mucambos. 12 ed. Rio de Janeiro, RJ: Record.

Fry, P., \& Maggie, Y. (2006). Apresentação. In N. Rodrigues, O animismo fetichista dos negros baianos (pp. 9-21). Rio de Janeiro, RJ: UFRJ.

Ginsberg, A. M. (1955) Pesquisas sobre as atitudes de um grupo de escolares de São Paulo em relação com as crianças de cor. In R. Bastide, \& F. Fernandes, Relações raciais entre brancos e negros em São Paulo (311-361). São Paulo, SP: Anhembi. 
Guimarães, A. S. (2002). Classes, raça e democracia. São Paulo, SP: Ed. 34.

Guimarães, A. S. (2005). Racismo e anti-racismo no Brasil (2a ed.). São Paulo, SP: Ed. 34.

Guimarães, A. S. (1999). Raça e os estudos de relações raciais no Brasil. Novos Estudos Cebrap, (54), 147-156.

Hasenbalg, C. (1979). Discriminação e desigualdades raciais no Brasil. Rio de Janeiro, RJ: Graal.

Herschmann, M. M., \& Pereira, C. A. M. (Orgs.). (1994) A invenção do Brasil moderno: medicina, educação e engenharia nos anos 20-30. Rio de Janeiro, RJ: Rocco.

Jacó-Vilela, A. M., Jabur, F., \& Rodrigues, H. C. (Orgs.). (1999). Clio-Psyché: histórias da Psicologia no Brasil (Biblioteca virtual de ciências humanas). Rio de Janeiro, RJ: Nape/UERJ.

Leite, D. M. (2002). O caráter nacional brasileiro: história de uma ideologia (6a ed., Série Dante Moreira Leite). São Paulo, SP: Editora UNESP.

Leite, D. M. (2008). Psicologia diferencial e estudos em educação (Série Dante Moreira Leite). São Paulo, SP: Editora UNESP.

Lourenço Filho, M. B. (1994). A psicologia no Brasil. In F. Azevedo (Org.), As ciências no Brasil (2a ed., pp. 301-341). Rio de Janeiro, RJ: Editora UFRJ.

Maio, M. C. (2000). O projeto Unesco: ciências sociais e o "credo racial brasileiro". Revista USP. (46), 115-128). https://doi.org/10.11606/issn.2316-9036.v0i46p115-128

Martins, H. V. (2014). Da África às faculdades de medicina: um estudo do elemento negro na sociedade brasileira. In M. A. S. Bento, M. J. Silveira, \& S. G. Nogueira, Identidade, branquitude e negritude: contribuições para a psicologia social no Brasil: novos ensaios, relatos de experiência e de pesquisa (pp. 275-312). São Paulo, SP: Casa do Psicólogo.

Martins, H. V., \& Silva, N. S. (2013). A produção de uma cultura africana no Brasil e sua relação com os saberes psicológicos. In: C. R. Carvalho, R. Nogueira, \& S. R. Sales (Orgs.), Relações étnico-raciais e educação: contextos, práticas e pesquisas (pp. 157-168, Série Docência). Rio de Janeiro, RJ: Seropédica.

Nunes, S. S. (2006). Racismo no Brasil: tentativas de disfarce de uma violência explícita. Psicologia USP, 17(1), 89-98. https://doi.org/10.1590/S0103-65642006000100007

Oda, A. M. G. R. (2003). Alienação mental e raça: a psicopatologia comparada dos negros e mestiços brasileiros na obra de Raimundo Nina Rodrigues. Tese de doutorado. Universidade Estadual de Campinas, Campinas, SP.

Paiva, G. J. (2000). Dante Moreira Leite: um pioneiro da psicologia social no Brasil. Psicologia USP, 11(2), 25-57. https://doi.org/10.1590/S0103-65642000000200003

Peixoto, A. (1938a). Clima e saúde: introdução bio-geográfica à civilização brasileira (Coleção Biblioteca pedagógica brasileira, Vol. 129). São Paulo, SP: Companhia Editora Nacional.

Peixoto, A. (1898). Epilepsia e crime. Salvador, BA:V. Oliveira \& Companhia.

Peixoto, A. (1938b). Prefácio. In R. N. Rodrigues, As raças humanas e a responsabilidade penal no Brasil (pp. 11-26). Rio de Janeiro, RJ: Guanabara.

Ramos, A. (1937). As culturas negras no Novo Mundo. Rio de Janeiro, RJ: Civilização Brasileira.

Ramos, A. (2003). Introdução à psicologia social. São Paulo, SP: Caso do Psicólogo.

Ramos, A. (2007). O folclore negro do Brasil: demopsicologia e psicanálise (3a ed., Série Raízes). São Paulo, SP: Martins Fontes.

Ramos, A. (1934). O negro brasileiro, etnografia religiosa e psicanálise. Rio de Janeiro, RJ: Civilização Brasileira.

Ramos, A. (1939). Prefácio. In R. N. Rodrigues, As coletividades anormais (pp. 9-24, Biblioteca de divulgação científica, Vol. 19). Rio de Janeiro, RJ: Civilização Brasileira.

Rodrigues, R. N. (1939). As coletividades anormais (Biblioteca de Divulgação Científica, Vol. 19). Rio de Janeiro, RJ: Civilização Brasileira.

Rodrigues, R. N. (1894). As raças humanas e a responsabilidade penal no Brasil. Salvador, BA: Imprensa Popular.

Rodrigues, R. N. (2006). O animismo fetichista dos negros baianos. Rio de Janeiro, RJ: Fundação Biblioteca Nacional. 
Rodrigues, R. N. (1935). Os africanos no Brasil (2a ed., Biblioteca Pedagógica Brasileira, série V. Vol. 9). São Paulo, SP: Companhia Editora Nacional.

Sá, C. P. (2007). Sobre a psicologia social no Brasil, entre memórias históricas e pessoais. Psicologia \& Sociedade, 19(3): 7-13. https://doi.org/10.1590/S0102-71822007000300002

Sales, F. (1988). Notas bibliográficas de Nina Rodrigues. In R. N. Rodrigues, Os africanos no Brasil (7a ed., pp. 277-283). São Paulo, SP: Editora Nacional.

Santos, A. O., \& Schucman, L. V. (2015). Desigualdade, relações raciais e a formação de psicólogo(as). Revista EPOS, 6(2), 117-140. Disponível em: http://pepsic.bvsalud.org/scielo.php?script=sci_arttext\&pi$\mathrm{d}=$ S2178-700X2015000200007\&lng=pt\&tlng=pt

Santos, A. O., Schucman, L. V., \& Martins, H. V. (2012) Breve histórico do pensamento psicológico brasileiro sobre relações étnico-raciais. Psicologia: Ciência e Profissão, 32(no spe),166-175. https://doi.org/10.1590/S1414-98932012000500012

Santos, N. S. (1983). Torna-se negro: as vicissitudes da identidade do negro brasileiro em ascensão social. Rio de Janeiro, RJ: Graal.

Schwarcz, L. M. (1993). O espetáculo das raças: cientistas, instituições e questão racial no Brasil. São Paulo, SP: Companhia das Letras.

Schucman, L. V. (2012). Entre o "encardido", o "branco" e o "branquíssimo": raça, hierarquia e poder na construção da branquitude paulistana (Tese de doutorado). Universidade de São Paulo, SP.

Schucman, L.V. (2010). Racismo e antirracismo: a categoria raça em questão. Revista Psicologia Política, 10(19), 41-55. Recuperado de http://pepsic.bvsalud.org/scielo.php?script=sci_arttext\& pid=S1519=549-2010000100005X\&lngpt\&nrm =iso\&tlng=pt

Schucman, L. V., Nunes, S. S., \& Costa, E. S. (2017). A Psicologia da Universidade de São Paulo e as relações raciais: perspectivas emergentes. Psicologia USP, 28(1), 144-158. https://doi.org/10.1590/0103-6564a20132413

Sennet, R. (1988). O declínio do homem público: as tiranias da intimidade. São Paulo, SP: Companhia das Letras.

Skidmore, T. (1976). Preto no branco: raça e nacionalidade no pensamento brasileiro. Rio de Janeiro, RJ: Paz e Terra.

Tavares, N. O., Oliveira, L. V., \& Lages, S. R. C. (2013). A percepção dos psicólogos sobre o racismo institucional na saúde pública. Saúde em Debate, 37(99), 580-587. https://doi.org/10.1590/S0103-11042013000400005

Telles, E. E. (2003). Racismo à brasileira: uma nova perspectiva sociológica. Rio de Janeiro, RJ: Relume Dumará.

\section{Lia Vainer Schucman}

Graduação em Psicologia pela Universidade Federal de Santa Catarina, Florianópolis - SC. Brasil. Mestrado em Psicologia pela Universidade Federal de Santa Catarina. Doutorado e pós-doutorado em Psicologia Social pela Universidade de São Paulo, São Paulo - SP. Brasil.

E-mail: liavainers@gmail.com

\section{Hildeberto Vieira Martins}

Professor Doutor do Departamento de Psicologia Social da Universidade Federal Fluminense, Rio de Janeiro - RJ. Brasil. E-mail: betohvm@vm.uff.br

Endereço para envio de correspondência:

Rua: Ernesto Meyer Filho 368. Porto da Lagoa.

Florianópolis - SC. Brasil.

Rua Conde De Baependi, 124/604 - Flamengo. CEP: 22231-140.

Rio de Janeiro - RJ. Brasil. 
Recebido 29/06/2017

Reformulação 29/09/2017

Aprovado 02/102017

Received $06 / 29 / 2017$

Reformulated 09/29/2017

Approved 10/02/2017

Recebido 29/06/2017

Reformulado 29/09/2017

Aceptado 02/10/2017

Como citar: Schucman, L. V., Martins H. V. (2017). A Psicologia e o discurso racial sobre o negro: do "objeto da ciência" ao sujeito político. Psicologia: Ciência e Profissão, 37(n. spe), 172-185. https://doi.org/10.1590/1982-3703130002017

How to cite: Schucman, L. V., Martins H. V. (2017). Psychology and racial discourse on black people: from “object of science" to political subject. Psicologia: Ciência e Profissão, 37(n. spe), 172-185. https://doi.org/10.1590/1982-3703130002017

Cómo citar: Schucman, L. V., Martins H. V. (2017). Psicología y discurso racial acerca del negro: de "objeto de la ciencia" a sujeto político. Psicologia: Ciência e Profissão, 37(n. spe), 172-185. https://doi.org/10.1590/1982-3703130002017 